\title{
SUBSÍDIOS PARA A GESTÃO COMPARTILHADA DA PESCA NA BAÍA DA BABITONGA (SC, BRASIL)
}

\author{
SERAFINI, T. Z. ${ }^{1 *}$; ANDRIGUETTO-FILHO, J. M. ${ }^{2,4}$ \& PIERRI, N. ${ }^{3,4}$ \\ 1 - Departamento de Ciências do Mar - DCMar, Universidade Federal de São Paulo - UNIFESP \\ 2 - Departamento de Zootecnia, Universidade Federal do Paraná - UFPR \\ 3 - Centro de Estudos do Mar - CEM, Universidade Federal do Paraná - UFPR \\ 4 - Programa de Pós-Graduação em Meio Ambiente e Desenvolvimento - PPGMADE, UFPR \\ *Corresponding author: thiago.serafini@unifesp.br
}

\begin{abstract}
Serafini, T.Z.; Andriguetto-Filho, J.M.; Pierri, N. (2014) Support to fisheries co-management at Babitonga Bay, southern Brazil. Braz. J. Aquat. Sci. Technol. 18(1): 99-111. elSSN 1983-9057. DOI: 10.14210/bjast.v18n1.p99-111 This study characterizes the fisheries at Babitonga Bay, in the northern coast of Santa Catarina (Brazil), in order to point out management implications of local contexts. Qualitative and quantitative surveys were conducted at 12 fishing localities in the region, assessing fishing practices, socioeconomic features, and aspects of the institutional organization of fishermen. A great variety of small-scale fishing practices and resources was observed, as well as different ways of fishing commercialization, with considerable differences between localities, resulting in part from differences in spatial use patterns. Despite the existence of a few local associations, so-called "Colônias de Pesca" were the main representative organizations. Yet, not all fishermen acknowledged their importance. A low degree of political organization of the fishermen was observed, as well as an apparent lack of leadership, moderate participation in representative fora ("Colônias") and disagreement regarding group union perception. In their own opinion, their interactions with fisheries management government agencies, as well as with partner non-governmental organizations, were weak. Thus, while they realize the worsening conditions of local fisheries, which require management interventions, fishermen find it difficult to communicate with the organizations in charge. Differences in fishery resources use patterns also potentially increase complexity for local fisheries management. Changes in the local fisheries management perspective are needed, with an emphasis on the establishment of collaborative management arrangements (co-management), which could better deal with the complexity of the local fishery context, thus ensuring greater institutional effectiveness.
\end{abstract}

\begin{abstract}
Keywords: small-scale fisheries, fisheries management, resource appropriation, fishermen participation, fishermen organizations, co-management.
\end{abstract}

\section{INTRODUÇÃO}

Os sistemas socioecológicos da pesca costeira e estuarina no Brasil caracterizam-se por pescarias de pequena escala (ou artesanais), com distintas particularidades técnicas, econômicas, sociais e culturais (Diegues, 2004; Isaac et al., 2006). No Brasil, são registrados cerca de 1 milhão de pescadores da pesca de pequena escala - PPE (MPA, 2012), responsáveis por metade $(52,5 \%)$ da produção pesqueira nacional (Vasconcellos et al., 2007). Na região sul, especialmente em Santa Catarina, a PPE representa uma importante atividade socioeconômico-cultural, com diversas comunidades pesqueiras distribuídas ao longo do litoral (Medeiros et al., 1997; Sunye, 2006).

A escassez de informações de produção pesqueira, da biologia dos recursos, das práticas de pesca, de aspectos socioeconômicos e culturais dos pescadores da PPE é amplamente reconhecida no Brasil (Vasconcellos et al., 2007) e no mundo (Johannes, 1998; Berkes et al., 2001). Estima-se que $58 \%$ das principais pescarias de pequena escala do sul do Brasil está em declínio ou em colapso, sugerindo a necessidade de medidas de manejo e redução de esforço de algumas pescarias, tanto da PPE quanto da pesca industrial, considerando que muitos dos estoques são compartilhados por ambas (Vasconcellos et al., 2007).

Como destaca Berkes (2003), na PPE a pesca não é somente um trabalho que provê renda e alimento, mas sim um modo de vida, que inclui múltiplas atividades, de caráter perene ou sazonal, e a participação de familiares, daí a necessidade de inclusão dos aspectos socioeconômicos e culturais no processo de gestão. As dificuldades de obter informações destes sistemas socioecológicos pesqueiros resultam da sua própria complexidade (Mahon et al., 2008). Sua gestão envolve mais do que um "único" objetivo (manter os estoques em níveis sustentáveis de explotação), mas sim múltiplos objetivos de caráter biológico, econômico, social e cultural (Berkes et al., 2001; Castello, 2008). Nesse sentido, torna-se importante a ampla participação dos pescadores nos arranjos institucionais de gestão, pelo seu direito democrático, pela importância de seu conhecimento ecológico local, e para considerar adequadamente a diversidade de usos e formas de apropriação dos recursos pesqueiros.

Na região do litoral norte de Santa Catarina, no entorno da Baía da Babitonga, Bastos (2006) estimou 
cerca de 1770 pescadores, distribuídos em mais de 30 comunidades e atuando dentro do estuário e na plataforma ou mar aberto. A pesca está presente nos seis municípios do entorno da baía, sendo bastante expressiva na economia de alguns deles, como Balneário Barra do Sul e São Francisco do Sul, e também na produção pesqueira artesanal do estado, com cerca de $15 \%$ da produção estadual, segundo PROZEE (2006). A natureza da região encontra-se relativamente em bom estado de conservação e concentra a maior extensão de manguezais do estado (IBAMA, 1998), apesar do histórico de degradação e contaminação de alguns ambientes (Cremer et al., 2006).

Estudos anteriores da pesca na Baía da Babitonga descreveram alguns dos seus aspectos técnicos, socioeconômicos e culturais (IBAMA, 1998; Pinheiro \& Cremer, 2003; Bastos, 2006). O presente trabalho procura avançar sobre essa base de conhecimentos e descrever atributos da pesca local relevantes para um enfoque de gestão compartilhada (cogestão), abrangendo as práticas de pesca, os recursos explotados, as áreas de atuação, os aspectos socioeconômicos e de organização institucional. Através deste trabalho se mostrou a heterogeneidade da pesca na Baía da Babitonga, que se caracteriza por diferentes grupos de pescadores e práticas de pesca, atuando em áreas com diversos graus de compartilhamento e com características socioeconômicas relativamente diferenciadas. Também são apresentadas as percepções dos pescadores sobre os recursos explotados, o papel e a relevância das instituições e de sua organização, além da forma de gestão em vigor. Estas informações são relevantes enquanto subsídios para a construção de um processo de gestão compartiIhada da pesca na região, pois o conhecimento das condições locais anteriores à implementação dos arranjos aumenta as chances de sucesso das iniciativas, evitando arranjos prematuros ou equivocados de cogestão (Chuenpagdee \& Jentoft, 2007).

\section{MATERIAIS E MÉTODOS}

\section{Área de Estudo}

A Baía da Babitonga está localizada no litoral norte de Santa Catarina, compreendendo seis municípios em seu entorno: Itapoá, Garuva, Joinville, Araquari, Baln. Barra do Sul e São Francisco do Sul (Figura 1). A baía está inserida na planície costeira (ou quaternária), ocupando uma faixa de aproximadamente $35 \mathrm{~km}$ entre a Serra do Mar e o oceano Atlântico. O clima é subtropical úmido, com alto índice pluviométrico (média anual acima de $2000 \mathrm{~mm}$ ) e uma série de rios deságua no estuário, principalmente na porção norte (rio Palmital). Os bosques de mangue são bem desenvolvidos, ocupando uma área de aproximadamente $6200 \mathrm{ha}$, com as maiores extensões na porção interna da baía, principalmente ao longo do rio Palmital. O estuário apresenta uma lâmina da água de $153,7 \mathrm{~km}^{2}$, com uma barra principal ao norte com $1850 \mathrm{~m}$ de largura. Possuía uma segunda barra menor ao sul, na desembocadura do Canal do Linguado, que foi interrompida por um aterro no canal, em 1935. A porção externa da baía apresenta extensas praias arenosas, enseadas, costões rochosos e ilhas marinhas, com destaque para o Arquipélago da llha da Paz, dos Tamboretes e da Ilha dos Remédios (IBAMA, 1998; Knie, 2003).

\section{Comunidades estudadas}

O estudo foi realizado em 12 comunidades de pesca distribuídas nos seis municípios do entorno da Baía da Babitonga, dentro do estuário e ao longo da costa, a saber: Itapema do Norte e Pontal-Figueira (município de Itapoá); Barrancos (Garuva); Vigorelli e Morro do Amaral (Joinville); Araquari (Araquari); Barra do Sul (Baln. Barra do Sul); e Enseada, Iperoba, Paulas, Praia do Lixo e Estaleiro-Frias (São Francisco do Sul) (Figura 1).

Em cada comunidade, foram selecionados como informantes pescadores experientes no conhecimento sobre a pesca e sua comunidade, através de indicação de outros pescadores, comunitários, membros da Colônia de Pesca, técnicos de extensão pesqueira e/ou pesquisadores com experiência na região. Buscou-se abranger pescadores que atuavam nas diversas práticas de pesca presentes. O número de informantes variou entre três e oito por comunidade, totalizando 55 .

\section{Levantamento e análise dos dados}

Entrevistas semi-estruturadas foram aplicadas aos informantes entre dezembro de 2010 e maio de 2011, visando obter informações qualitativas de aspectos das pescarias praticadas, dos recursos explotados, de aspectos socioeconômicos e das instituições e organizações dos pescadores e de outras que intervêm na gestão (governo, ONGs e universidades).

Com dados fornecidos por pouco mais da metade dos informantes $(n=28)$ foram também realizados mapeamentos participativos, para a identificação das áreas de pesca de algumas pescarias em cada comunidade, tendo como base uma imagem de satélite da região na escala de 1:90000. O procedimento para cada informante consistiu na identificação inicial de alguns pontos específicos da região, incluindo a comunidade do pescador em questão e, posteriormente, o delineamento das áreas gerais de pesca indicadas por ele, e não necessariamente de pontos específicos ou pesqueiros. 


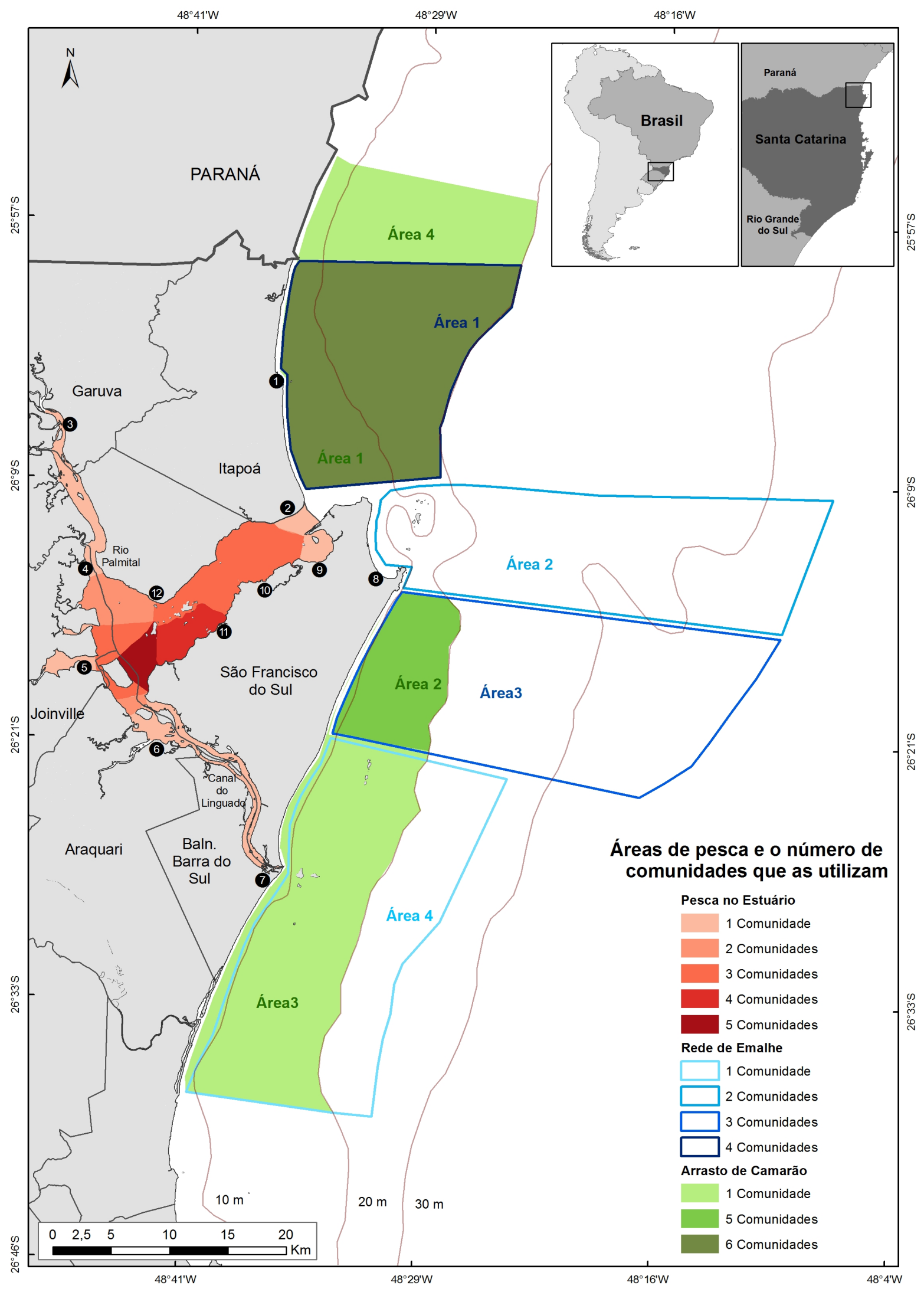

Figura 1 - Áreas de pesca estuarinas e da plataforma, e o número de comunidades de pesca estudadas da Baía da Babitonga-SC que as utilizam. Comunidades de pesca: 1 = Itapema do Norte; $2=$ Pontal-Figueira; $3=$ Barrancos; $4=$ Vigorelli; $5=$ Morro do Amaral; $6=$ Araquari; 7 = Barra do Sul; 8 = Enseada; 9 = Iperoba; 10 = Paulas; 11 = Praia do Lixo; e 12 = Estaleiro-Frias. 
Para a análise das entrevistas, as informações foram tabuladas conforme a temática (práticas de pesca, recursos explotados, área de atuação, aspectos socioeconômicos, organizações e instituições), e analisadas com relação ao conteúdo de cada assunto por informante e comunidade. No caso dos mapeamentos participativos, as lâminas de cada informante foram sobrepostas e foi gerado um mapa síntese de cada comunidade. Posteriormente, estes mapas foram digitalizados em software ArcGIS 9.3 e consolidados em mapas das áreas de uso por pescaria e/ou ambiente (estuário e plataforma) em bases cartográficas do IBGE (2008) na escala 1:50000 (Datum SAD 69).

\section{RESULTADOS}

\section{Práticas de pesca, recursos explotados e área de atuação}

Onze práticas de pesca foram mais comuns na região (Tabela 1): arrasto de portas (duplo ou simples), para a captura de camarões na plataforma; gerival, para a captura de camarões no estuário; emalhe redondo, usado em mar aberto e no estuário; caceio de camarões (com a malha $5 \mathrm{~cm}$ entre nós opostos) e de peixes (com diversos tamanhos de malha); emalhe de fundeio; arrastão de praia; espinhel; linha e anzol; tarrafa; e práticas de coleta de moluscos e crustáceos, manualmente ou com auxílio de petrechos, como o puçá para siris. Algumas práticas recebem denominações diferentes (p.ex. "fundeio" ou "palanqueada", "redondo" ou "caça-e-malha"), conforme a comunidade (para uma descrição das práticas, ver IBAMA, 1998 e Serafini, 2012).

A diversidade de práticas utilizadas variou entre as comunidades estudadas e foi possível identificar quatro grupos distintos, explicados pela posição das mesmas na região (Tabela 1). Em um grupo (1) estariam as comunidades próximas à desembocadura da baía, onde os pescadores podem atuar tanto na plataforma quanto no estuário, e, por isso, utilizam um maior número de práticas. Outro grupo (2) corresponde às comunidades da porção central ao fundo da baía, cujos pescadores atuam somente no estuário sendo que sua principal diferença com relação ao grupo anterior é a ausência da pesca com arrasto de portas, realizado somente na plataforma.

As comunidades pertencentes a outro grupo (3) foram aquelas situadas na orla oceânica e onde os pescadores utilizam apenas a plataforma como área de pesca; portanto, sua principal diferença com relação ao grupo anterior é a não captura do camarão-branco no estuário, normalmente realizado com o gerival, sendo um grupo centrado na pesca do arrasto com portas. Por fim, no último grupo (4), os pescadores atuam na porção mais interna do estuário (Rio Palmital), com menor diversidade de práticas, voltadas especialmente para a captura de peixes e a coleta de moluscos e crustáceos, uma vez que o camarão é praticamente ausente no local.

De forma geral, os pescadores trabalham com mais de uma prática, alternando-as ao longo do ano,

Tabela 1 - Comunidades de pesca da Baía da Babitonga-SC agrupadas de acordo com as principais práticas de pesca utilizadas. Práticas de pesca: Arr = Arrasto de portas; Ger = Gerival; Red = Emalhe redondo; Cac $=$ Caceio de camarão; Cap = Caceio de peixes; Fun = Emalhe de fundeio; Esp = Espinhel; Lin = Linha e anzol; Arp = Arrastão de praia; Tar = Tarrafa; Col = Coleta de moluscos e crustáceos. O número ao lado de cada comunidade corresponde a sua localização na Figura 1.

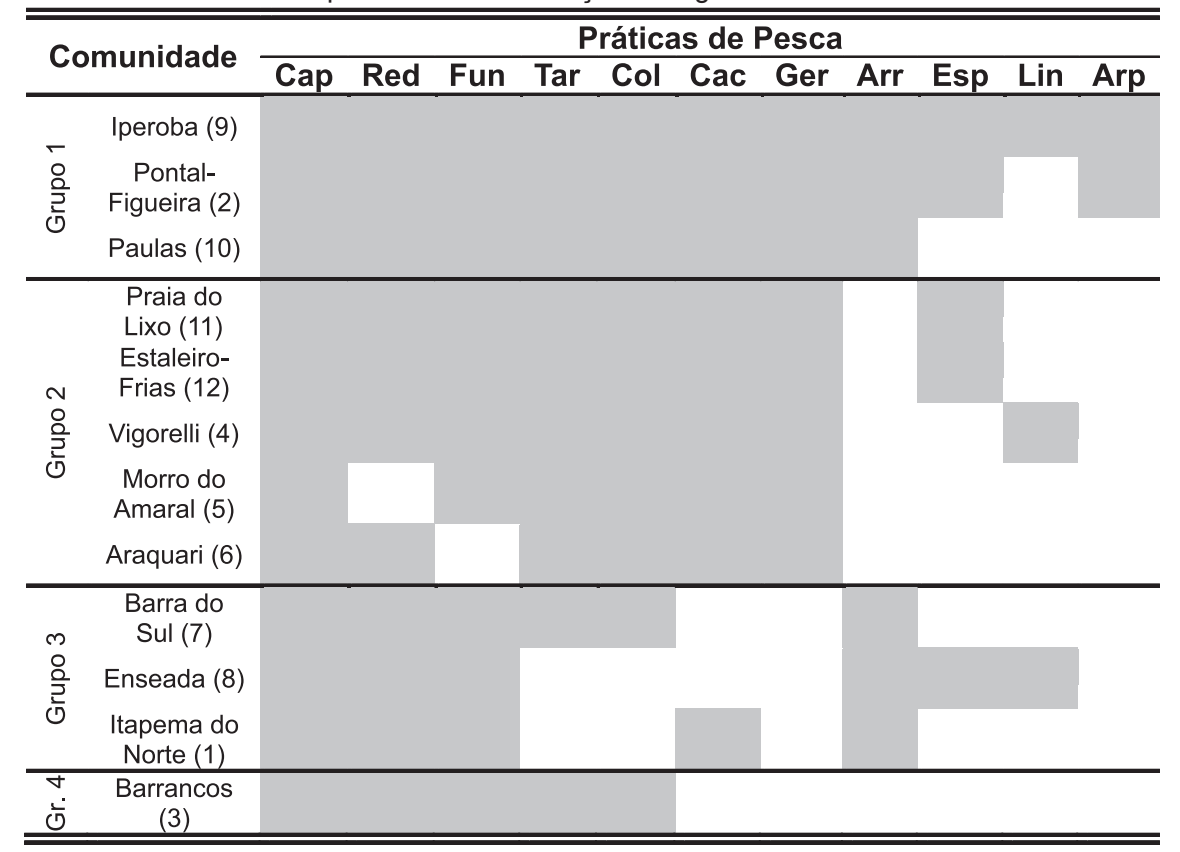


conforme o recurso explotado, mas também podem se dedicar predominantemente a uma pescaria (p.ex. o arrasto para camarão). Isto é evidente pela sazonalidade da explotação de alguns recursos importantes na região, como no caso do camarão-branco dentro do estuário, onde se alternam os petrechos (gerival e caceio) conforme a eficiência de captura do recurso (Tabela 2). Alguns recursos podem estar disponíveis somente em uma época do ano (p.ex. miraguaia, linguado) ou o ano todo (p.ex. parati), mas em alguns casos com maior abundância em um período específico (p.ex. tainha, camarão-sete-barbas).

A importância relativa dos recursos para a renda dos pescadores pode variar conforme a comunidade (Tabela 3). Os camarões (branco e sete-barbas) se destacaram como recurso importante ou muito importante em 11 das 12 comunidades. A exceção é Barrancos, em Garuva, em que os peixes são mais importantes, dada sua posição mais interiorana no estuário e a ausência da captura de camarões. Além dos camarões, em algumas comunidades, especialmente do interior da baía, peixes como robalo, pescadinha e parati, ou moluscos e crustáceos, como a ostra, bacucu, siri e caranguejo, podem se destacar como recursos mais importantes.

A quase totalidade das embarcações utilizadas possui motor de popa ou de centro, variando consideravelmente na potência (de 2 a $145 \mathrm{Hp}$ ), bem como no comprimento (de 3,5 a $14 \mathrm{~m}$ ). Predomina o uso das bateiras, dentro da baía, e dos botes, em mar aberto. As maiores embarcações e com maior potência estão nas comunidades da orla e desembocadura da baía (Barra do Sul, Enseada, Itapema do Norte, Paulas,
Iperoba e Pontal-Figueira) e as menores na porção central e no interior do estuário.

A comparação das áreas de uso das 12 comunidades estudadas revelou que, no estuário, algumas áreas de pesca são mais compartilhadas pelas comunidades do que outras. A porção central da baía, nas proximidades das ilhas, se mostra como uma área de pesca bastante compartilhada, enquanto as regiões do rio Palmital e do Canal do Linguado (porção norte e sul em relação ao aterro) são utilizadas apenas por pescadores das comunidades dos Barrancos e Araquari/Barra do Sul, respectivamente (Figura 1).

No que diz respeito à pesca na plataforma, foram identificadas cinco áreas principais de pesca de arrasto e de redes de emalhe (caceio e fundeio) (Figura 1). No caso do arrasto, estas áreas se estendem, ao norte, do Morro do Cristo, em Guaratuba, no Paraná ( $\left.25^{\circ} 53^{\prime} \mathrm{S}, 48^{\circ} 33^{\prime} \mathrm{W}\right)$ até, ao sul, nas proximidades de Barra Velha (26 $\left.37^{\prime} \mathrm{S}, 48^{\circ} 40^{\prime \prime} \mathrm{W}\right)$. As profundidades variaram de um mínimo de $3 \mathrm{~m}$ a um máximo de $20 \mathrm{~m}$. Das quatro áreas identificadas, a Área 1, localizada em frente ao município de Itapoá, foi compartilhada por mais comunidades estudadas da baía, seguida pela Área 2, em frente à Praia Grande, em São Francisco do Sul (Figura 1). Porém, os pescadores também se deslocam para além desta região, principalmente até a divisa do litoral do Paraná com São Paulo.

No caso da pesca de redes de emalhe, o limite norte está nas proximidades da ilha do Saí (divisa de

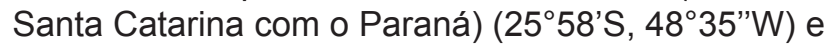
o limite sul próximo a Barra Velha ( $\left.26^{\circ} 37^{\prime} \mathrm{S}, 48^{\circ} 40^{\prime \prime} \mathrm{W}\right)$. As profundidades variaram de 3 a $40 \mathrm{~m}$ e das quatro áreas identificadas, a Área 1, em frente à Itapoá, foi

Tabela 2 - Períodos de safra de alguns recursos pesqueiros capturados na Baía da Babitonga-SC. G = uso do gerival; e C = uso do caceio para camarão. Fonte: Presente trabalho, Bastos (2006) e Pinheiro \& Cremer (2003).

\begin{tabular}{|c|c|c|c|c|c|c|c|c|c|c|c|c|}
\hline \multirow{2}{*}{$\begin{array}{l}\text { Nome vulgar } \\
\text { (Espécie) }\end{array}$} & \multicolumn{12}{|c|}{ Meses } \\
\hline & $\mathrm{J}$ & $F$ & $M$ & A & $M$ & $\mathrm{~J}$ & $\mathrm{~J}$ & A & s & 0 & $\mathbf{N}$ & D \\
\hline $\begin{array}{l}\text { Camarão-branco } \\
\text { (Litopenaeus schimitti) }\end{array}$ & $\mathbf{G}$ & $\overline{\mathbf{G}}$ & $\mathbf{G}$ & G & C & C & C & & & & & \\
\hline $\begin{array}{l}\text { Camarão-ferro } \\
\text { (Farfantepenaeus paulensis) }\end{array}$ & & & & & & & & & & & & \\
\hline $\begin{array}{l}\text { Camarão-sete-barbas } \\
\text { (Xiphopenaeus kroyeri) }\end{array}$ & & & & & & & & & & & & \\
\hline $\begin{array}{l}\text { Caranguejo } \\
\text { (Ucides cordatus) }\end{array}$ & & & & & & & & & & & & \\
\hline $\begin{array}{l}\text { Tainha } \\
\text { (Mugil spp.) }\end{array}$ & & & & & & & & & & & & \\
\hline $\begin{array}{l}\text { Parati } \\
\text { (Mugil spp.) }\end{array}$ & & & & & & & & & & & & \\
\hline $\begin{array}{l}\text { Pescadinha } \\
\text { (/ssopisthus sp.) }\end{array}$ & & & & & & & & & & & & \\
\hline $\begin{array}{l}\text { Corvina } \\
\text { (Micropogonias furnieri) }\end{array}$ & & & & & & & & & & & & \\
\hline $\begin{array}{l}\text { Linguado } \\
\text { (Bothidae e Paralichthyidae) }\end{array}$ & & & & & & & & & & & & \\
\hline $\begin{array}{l}\text { Miraguaia } \\
\text { (Pogonias cromis) }\end{array}$ & & & & & & & & & & & & \\
\hline $\begin{array}{l}\text { Pescada Amarela } \\
\text { (Cynoscion acoupa) }\end{array}$ & & & & & & & & & & & & \\
\hline $\begin{array}{l}\text { Guaivira } \\
\text { (Oligoplites spp.) }\end{array}$ & & & & & & & & & & & & \\
\hline
\end{tabular}


Serafini et al.: Pesca e gestão na Baía da Babitonga-SC

Tabela 3 - Importância dos recursos pesqueiros para a renda dos pescadores da Baía da Babitonga-SC.

\begin{tabular}{|c|c|c|}
\hline Comunidade & Mais importante & Importante \\
\hline $\begin{array}{l}\text { Itapema do } \\
\text { Norte }\end{array}$ & $\begin{array}{l}\text { Camarão-sete-barbas } \\
\text { (Xiphopenaeus kroyeri) }\end{array}$ & $\begin{array}{l}\text { Camarão-branco (Litopenaeus schimitti); } \\
\text { Cavala (Scomberomorus spp.); Linguado } \\
\text { (Bothidae, Paralichtyidae); Robalo } \\
\text { (Centropomus spp.); Tainha (Mugil spp.); } \\
\text { Sororoca (Scomberomorus brasiliensis) }\end{array}$ \\
\hline $\begin{array}{l}\text { Pontal- } \\
\text { Figueira }\end{array}$ & Camarão-branco & $\begin{array}{l}\text { Camarão-sete-barbas; Linguado; Robalo; } \\
\text { Cavala; Tainha; Sororoca }\end{array}$ \\
\hline Barrancos & $\begin{array}{l}\text { Caratinga (Eugerres } \\
\text { brasilianus); Robalo }\end{array}$ & $\begin{array}{l}\text { Parati (Mugil spp.); Tainhota (Mugil spp.); } \\
\text { Caranguejo (Ucides cordatus) }\end{array}$ \\
\hline Vigorelli & $\begin{array}{l}\text { Camarão-branco; Marisco } \\
\text { (Mytella sp.); Bacucu (Mytela } \\
\text { charruana) }\end{array}$ & $\begin{array}{l}\text { Parati; Tainha; Pescada Amarela (Cynoscion } \\
\text { acoupa); Robalo; Caranguejo }\end{array}$ \\
\hline $\begin{array}{l}\text { Morro do } \\
\text { Amaral }\end{array}$ & $\begin{array}{l}\text { Camarão-branco; Ostra } \\
\text { (Crassostrea spp.); Siri } \\
\text { (Callinectes spp.); Bacucu; } \\
\text { Caranguejo }\end{array}$ & $\begin{array}{l}\text { Pescadinha (Isopisthus sp.); Tainha; Bagre } \\
\text { (Ariidae); Espada (Trichiurus lepturus) }\end{array}$ \\
\hline Araquari & $\begin{array}{l}\text { Tainha; Parati; Caranguejo; } \\
\text { Siri }\end{array}$ & Camarão-branco \\
\hline Barra do Sul & $\begin{array}{l}\text { Camarão-sete-barbas; } \\
\text { Tainha; Pescada (Cynoscion } \\
\text { spp.); Pescadinha }\end{array}$ & $\begin{array}{l}\text { Robalo; Guaivira (Oligoplites spp.); Corvina; } \\
\text { Cação (Lamnidae, Carcharhinidae, Triakidae, } \\
\text { Odontaspididae, Sphyrnidae, Alopiidae, } \\
\text { Qualidae); Linguado; Sororoca }\end{array}$ \\
\hline Enseada & $\begin{array}{l}\text { Camarão-sete-barbas; } \\
\text { Tainha }\end{array}$ & Cação; Corvina; Guaivira; Sororoca \\
\hline Iperoba & $\begin{array}{l}\text { Camarão-sete-barbas; } \\
\text { Parati; Camarão-branco }\end{array}$ & Tainha; Corvina; Betara (Menticirrhus spp.) \\
\hline Paulas & Camarão-sete-barbas & $\begin{array}{l}\text { Camarão-branco; Pescadinha; Linguado; } \\
\text { Sororoca }\end{array}$ \\
\hline Praia do Lixo & Camarão-branco & $\begin{array}{l}\text { Robalo; Pescada; Pescadinha; Miraguaia } \\
\text { (Pogonias cromis); Berbigão (Anomalocardia } \\
\text { brasiliana) }\end{array}$ \\
\hline $\begin{array}{l}\text { Estaleiro- } \\
\text { Frias }\end{array}$ & $\begin{array}{l}\text { Camarão-branco; Pescada } \\
\text { Amarela; Miraguaia }\end{array}$ & Tainha; Robalo; Ostra; Siri; Berbigão \\
\hline
\end{tabular}

compartilhada por mais comunidades, seguida da Área 3, em frente à Praia Grande, em São Francisco do Sul, e a Área 2, próxima à desembocadura da baía (Figura 1).

\section{Aspectos socioeconômicos}

Em quase todas as famílias, além do entrevistado, ao menos um membro da família participa de alguma atividade relacionada à pesca, seja acompanhando o pescador, beneficiando o pescado em terra ou comercializando a produção. Normalmente, a principal pessoa envolvida é a esposa, geralmente no beneficiamento do pescado. Os filhos também participam, mas muitos pescadores preferem que eles se dediquem aos estudos ou a outra atividade.

Os pescadores podem pescar sozinhos, principalmente com petrechos que não necessitam de outra pessoa para sua operação. Em quase todas as comunidades os acompanhantes da pesca são do núcleo familiar, mas também podem ser "camaradas", normalmente amigos ou parentes, ou pessoas sem um vínculo pessoal particular. Segundo os informantes, a maior parte é proprietária de sua embarcação, mas eventualmente arrendam embarcações de outros.

De forma geral, os pescadores se dedicam predominantemente à pesca, mas também diversificam suas atividades econômicas realizando serviços pontuais (biscates) com a intenção de complementar a renda, especialmente em momentos de escassez de pescado ou em períodos de defeso.

Os aspectos que norteiam as percepções dos pescadores quanto a continuar na pesca ou procurar por outra atividade incluem o fato de terem "tradição" na pesca, isto é, que seus pais e antepassados foram pescadores e eles desde crianças já pescavam, desenvolvendo as habilidades necessárias. Neste sentido, há um sentimento de que não saberiam outro ofício, e, pelo fato de não terem estudado ou ter estudado pouco, as oportunidades para fazer outra atividade diminuiriam ainda mais. Por outro lado, atrelado a esta "tradição" na pesca, há também gosto pela profissão. Apesar de todo o desgaste que a mesma impõe e as incertezas quanto aos rendimentos proporcionados, muitos declararam gostar de ser pescador, especialmente pela liberdade deles próprios decidirem sobre seu trabalho.

Boa parte dos pescadores entrevistados (87\%) tem a percepção de que a pesca está pior com relação à época em que começaram a pescar, em decorrência da "diminuição" de vários recursos, embora não fique claro se se trata de uma queda de abundância ou rendimentos. Por outro lado, também acreditam que por mais que estejam diminuindo os recursos, a condição de vida está melhor, pois hoje é mais fácil comercializar o pescado e ter acesso a serviços. Atualmente, as formas mais usuais para a comercialização do pescado 
são: diretamente no desembarque (normalmente nas praias), na casa do próprio pescador, a venda de "porta em porta" (para a vizinhança), em locais comunitários (bancas), em peixarias (próprias ou de terceiros), para restaurantes, para atravessadores, e entrepostos (Tabela 4). Alguns pescadores praticam a venda de camarões vivos (branco e ferro) para serem utilizados como isca-viva na pesca recreativa, principalmente no estuário.

As formas de comercialização variaram conforme a comunidade, mas é possível distinguir três grupamentos (Tabela 4). Um grupo (1) é constituído pelas comunidades onde os pescadores têm maiores opções em decorrência do turismo, uma vez que estão localizadas nos principais balneários de veraneio da região. As bancas construídas em parceira com as prefeituras municipais, bem como a venda direta para o turista na praia, são formas de comercialização não disponíveis nos demais grupos identificados.

Outro grupo (2) está formado pelas comunidades caracterizadas principalmente pela proximidade a áreas urbanas, permitindo, que o próprio pescador mantenha uma peixaria ou escoe o excesso da produção por atravessadores que as visitam. Por último, o grupo (3) inclui as comunidades mais isoladas ou especializadas na forma de comercialização, como Barrancos e Vigorelli, com maiores dificuldades de acesso ou estrutura, distribuindo a produção localmente, ou Paulas, onde, apesar de localizar-se na cidade de São Francisco do Sul, os pescadores direcionam boa parte da produção para revenda nas peixarias locais.

\section{Organizações e instituições}

Os pescadores artesanais profissionais da Baía da Babitonga estão organizados em seis Colônias de Pesca, uma em cada município. Além das Colônias, há um escritório regional do Sindicato dos Pescadores do Estado de Santa Catarina - SINDPESCA em Joinville, ao qual alguns pescadores da região estão associados. Existem, ainda, algumas associações locais de pescadores. Dentre todas estas organizações, as Colônias assumem o principal papel de entidades representativas da classe dos pescadores na região, com um total de 3236 associados (Tabela 5).

Mais da metade dos pescadores (58\%) declararam estar satisfeitos com sua Colônia (Tabela 6). Em geral, consideraram como ações que deveriam ser exercidas por elas: participação em programas de estímulo para a pesca artesanal; aquisição de equipamentos de pesca mais baratos; prestação de serviços jurídico e de saúde; maior envolvimento nos problemas locais; fomento de cooperativas; maior participação na definição da legislação pesqueira; maior exigência de fiscalização pelos órgãos responsáveis; e controle mais efetivo sobre a emissão dos atestados de comprovação da atividade pesqueira para a obtenção do Registro Geral da Pesca (RGP), uma vez que os pescadores se queixam da existência de pessoas sem vínculo efetivo com a pesca e que recebem os benefícios exclusivos da categoria (p.ex. seguro-defeso e indenizações por acidentes ambientais).

Apesar da maioria $(79 \%)$ considerar as reuniões da Colônia como um espaço importante para discussão e difusão de informações, somente $38 \%$ declarou participar sempre das reuniões, enquanto $5 \%$ nunca participam (Tabela 6). O aspecto citado como positivo para motivar a participação nas reuniões foi o de se manterem atualizados sobre as novas legislações ou políticas da pesca, mas com frequência disseram priorizar a participação apenas naquelas reuniões de maior interesse (p.ex. as que informam ou discutem questões como o seguro defeso e a carteira de pesca). Dentre os aspectos negativos para a participação nas reuniões, citaram: problemas de divulgação e deslocamento, principalmente nas comunidades mais afastadas da sede da Colônia; a forma de comunicação das informações, que dificulta a compreensão pelos

Tabela 4 - Comunidades de pesca da Baía da Babitonga-SC agrupadas de acordo com as principais formas de comercialização do pescado. Formas de comercialização: Des = desembarque; Cas = casa; Por = porta em porta; Ban = banca; Pep = peixaria do pescador; Pet $=$ peixaria de terceiro; Atr $=$ atravessador; Res = restaurante; Ent $=$ entreposto.

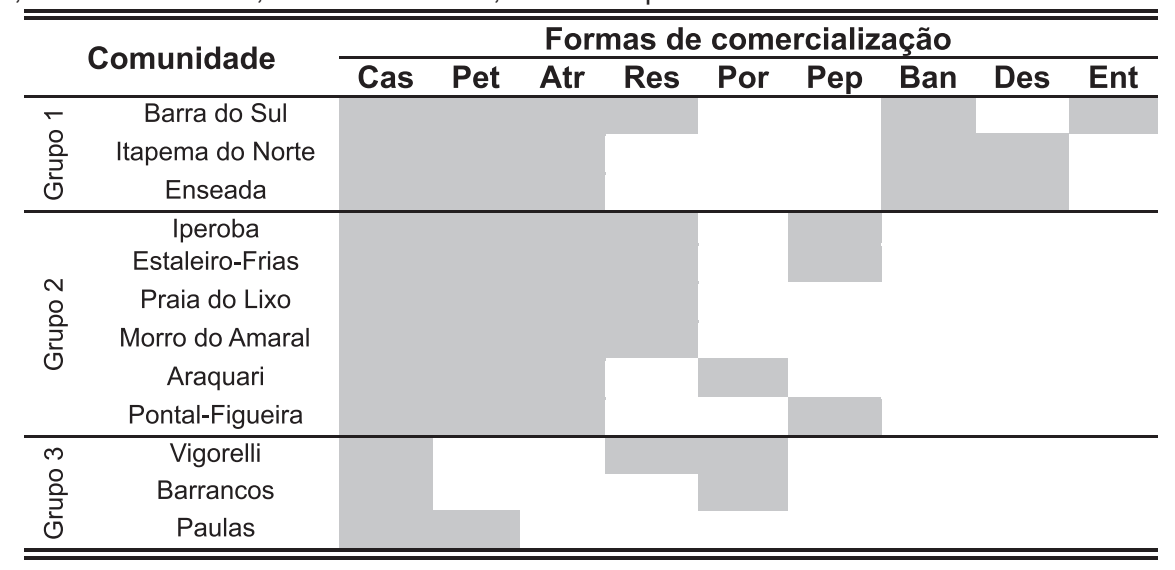


Tabela 5 - Organizações dos pescadores nos municípios da Baía da Babitonga-SC. Fonte: presente trabalho e Bastos (2006).

\begin{tabular}{lcccc}
\hline \hline Município & $\begin{array}{c}\text { Colônia } \\
\text { de } \\
\text { Pesca }\end{array}$ & $\begin{array}{c}\mathbf{N}^{\circ} \text { de } \\
\text { pescadores } \\
\text { cadastrados } \\
\text { na Colônia }\end{array}$ & Comunidades & $\begin{array}{c}\text { Outras organizações locais da } \\
\text { pesca }\end{array}$ \\
\hline Itapoá & Z-01 & 1.000 & $\begin{array}{c}\text { Itapema do Norte, } \\
\text { Pontal-Figueira }\end{array}$ & Não constatadas \\
\hline $\begin{array}{l}\text { São } \\
\text { Francisco } \\
\text { do Sul }\end{array}$ & Z-02 & 700 & $\begin{array}{c}\text { Enseada, Iperoba, } \\
\text { Paulas, Estaleiro- } \\
\text { Frias, Praia do Lixo }\end{array}$ & $\begin{array}{c}\text { Associação dos Pescadores } \\
\text { Profissionais da Enseada; } \\
\text { Associação de Mulheres } \\
\text { Pescadoras do Iperoba; } \\
\text { Associação dos Pescadores do } \\
\text { Paulas; Associação dos } \\
\text { Pescadores do Rocio Grande }\end{array}$ \\
\hline $\begin{array}{l}\text { Baln. Barra } \\
\text { do Sul }\end{array}$ & Z-03 & 580 & Barra do Sul & $\begin{array}{c}\text { Associação das Mulheres } \\
\text { Pescadoras de Balneário Barra do } \\
\text { Sul }\end{array}$ \\
\hline Garuva & Z-30 & 50 & Barrancos & Não constatadas \\
\hline Araquari & Z-31 & 180 & Araquari & Não constatadas \\
\hline Joinville & Z-32 & 726 & Vigorelli, Morro do & $\begin{array}{c}\text { Associação dos Pescadores e } \\
\text { Moradores da Vigorelli; Associação } \\
\text { de Moradores, Pescadores }\end{array}$ \\
\hline \hline
\end{tabular}

pescadores, especialmente quando há convidados externos (p.ex. representantes do Instituto Brasileiro do Meio Ambiente e dos Recursos Naturais Renováveis - IBAMA, Empresa de Pesquisa Agropecuária e Extensão Rural de Santa Catarina - EPAGRI, etc.); e que por vezes se sentiram frustrados, pois os assuntos são discutidos, mas depois nada acaba efetivamente acontecendo.

A maioria das associações locais da pesca, está desestruturada, algumas sem presidência e membros, e outras sem nenhum tipo de atuação recente. Estas associações locais são entidades usualmente formais, que reúnem pescadores de uma mesma comunidade, visando promover interesses específicos (p.ex. mulheres pescadoras) ou genéricos dos pescadores, mas por vezes sem um objetivo de ação muito claro. Quase metade (47\%) dos pescadores se considerou um grupo pouco unido para defender seus direitos e resolver os problemas da categoria; outra parcela $(26,5 \%)$ acha que são moderadamente unidos; e outra considera $(26,5 \%)$ que são unidos (Tabela 6). A maioria considera que os pescadores atuam de forma isolada, procurando sempre cuidar apenas de suas questões pessoais, dificilmente trabalhando em grupo. Aparentemente, não há uma presença de lideranças locais que ajudem na organização e defesa política dos pescadores.
Com relação aos órgãos de gestão pesqueira (Centro de Pesquisa e Gestão de Recursos Pesqueiros do Litoral Sudeste e Sul - CEPSUL, Ministério da Pesca e Aquicultura - MPA e IBAMA), constatou-se que os pescadores têm pouco conhecimento sobre os mesmos, e declaram que os agentes dessas organizações mantêm pouco contato com eles. A EPAGRI, que mantém escritórios em cada um dos municípios, foi o órgão governamental mais conhecido dentre os pescadores. Na maioria dos municípios, segundo os pescadores, a sua função se resume à execução do Programa Nacional de Fortalecimento da Agricultura Familiar - Pronaf, além do monitoramento participativo da pesca, que ocorreu em 2009. Por outro lado, apesar da imagem positiva da entidade relacionada aos benefícios gerados pelo Pronaf, a EPAGRI também recebeu críticas por priorizar a agricultura ou a maricultura, em detrimento da pesca. As Secretarias de Pesca, existentes em quatro dos seis municípios, são vistas como órgãos pouco atuantes, e os pescadores não identificam, claramente o papel desempenhado pelas mesmas. A exceção ocorreu em Baln. Barra do Sul, onde a consideram atuante, e informaram que disponibiliza alguns serviços para eles.

Os pescadores consideraram baixa a abertura dentro das organizações do governo para a sua participação. Quando questionados $(n=50)$ sobre quem de-

Tabela 6 - Posição dos pescadores da Baía da Babitonga-SC com relação a alguns aspectos de suas organizações e da união de grupo.

\begin{tabular}{|c|c|c|c|c|}
\hline Aspecto & Sim & Não & $\begin{array}{c}\text { Às vezes/ } \\
\text { Mais ou menos/ } \\
\text { Talvez }\end{array}$ & $n$ \\
\hline Participa nas reuniões da Colônia & $38 \%$ & $5 \%$ & $57 \%$ & 53 \\
\hline Acha importantes as reuniões da Colônia & $79 \%$ & $6 \%$ & $15 \%$ & 48 \\
\hline Está satisfeito com a Colônia & $58 \%$ & $34 \%$ & $8 \%$ & 52 \\
\hline Acha que há necessidade de outra organização & $18 \%$ & $80 \%$ & $2 \%$ & 45 \\
\hline Considera os pescadores unidos & $26,5 \%$ & $47 \%$ & $26,5 \%$ & 53 \\
\hline
\end{tabular}


veria ser responsável pela criação das regras da pesca (governo, pescadores ou "os dois juntos"), predominou a opinião "os dois juntos" (82\%). Consideraram que o pescador pode contribuir com o conhecimento prático da pesca na região, complementando os "estudos feitos pelo governo". Alguns (8\%) acreditam que somente o governo deveria ser responsável, já que eles têm estudos mais aprofundados e que os pescadores são desorganizados e com opiniões diversas. Outros (10\%) concordam que somente os pescadores deveriam defini-las, pois seriam os que realmente conhecem a pesca. Também consideraram que o governo não reconhece o conhecimento local dos pescadores para a concepção das leis relativas à pesca, pois estas priorizam apenas os estudos feitos pelo próprio governo e universidades.

Sobre outras organizações (organizações não-governamentais - ONGs e universidades), os pescadores entrevistados acreditam que mantêm pouco contato e que o retorno das mesmas para a resolução dos problemas locais da pesca é baixo. Depreende-se que o esforço institucional dessas organizações para questões ambientais e socioeconômicas da baía, não é percebido por grande parte dos pescadores.

Com relação à legislação pesqueira, constatou-se que nem todas as principais normas que incidem na região são de conhecimento dos pescadores ou que, quando as conhecem, por vezes não sabem exatamente o que é determinado por elas. Por outro lado, algumas leis são bem conhecidas e até mesmo questionadas quanto a sua validade, tal como os períodos de defeso dos camarões, dentro e fora da baía (Portaria $\mathrm{N}^{\circ} 70$, de 30 de outubro de 2003 e Instrução Normativa $\mathrm{N}^{\circ} 189$, de 23 de setembro de 2008 , respectivamente). Para os pescadores, os atuais períodos estipulados pela lei não abrangem a época que consideram correta.

No caso do defeso do camarão na plataforma, o período compreende de $1^{\circ}$ de março a 31 de maio que, para os pescadores, abrange a época da safra do sete-barbas. Baseados em seu conhecimento ecológico local, reivindicam sua alteração para outubro, novembro e dezembro, pois o período de primavera/ verão (setembro a março), quando a pesca está aberta, é justamente aquele em que capturam grande quantidade de fêmeas adultas ovadas e de juvenis em crescimento. A alteração do período visa a dois principais objetivos: (i) possibilitar a pescaria durante os meses de março a maio, por ser a época de maior abundância do camarão na região (safra); e (ii) proteger durante a primavera e início do verão as fêmeas adultas ovadas, garantindo a desova.

No caso do defeso do camarão no estuário, diferentemente do que se constatou para o camarão na plataforma, onde há certa coesão entre os pesca- dores com relação aos motivos para uma mudança da legislação atual e do período específico alternativo, não se conseguiu identificar tal coesão com os pescadores do interior da baía. Aparentemente, a principal motivação para a alteração do defeso seria a de permitir a captura do camarão-ferro. Segundo os pescadores, este camarão só está disponível nos meses de dezembro e janeiro, quando sua pesca está proibida pelo defeso. Sugerem a alteração do período, com duas posições: uma, antecipá-lo para o início da primavera (entre setembro e dezembro), e a outra, prorrogá-lo para janeiro a março. Na primeira opção, a justificativa seria de que antes de novembro (quando começa o atual defeso) o camarão-branco já estaria "graúdo" e as fêmeas ovadas, portanto seria o momento de fechar a pesca. Na segunda opção, no mês de fevereiro, quando abre a pesca, o camarão ainda estaria pequeno, sendo difícil capturá-lo com a malha determinada para o gerival na baía. Em ambas as propostas, o período entre dezembro e janeiro acabaria ficando de fora do defeso, o que favoreceria a captura do camarão-ferro.

Sobre o cumprimento do defeso, $17 \%$ dos 43 entrevistados declarou que os pescadores de sua comunidade nunca o respeitam. Entre os demais, parece haver níveis variáveis de obediência à norma, sem que ninguém a respeite estritamente.

As deficiências da fiscalização seriam, segundo os pescadores, um dos principais fatores responsáveis por grande parte dos problemas da pesca na região. A grande maioria $(71 \%)$ considerou a fiscalização ruim; enquanto apenas $12 \%$ a considerou boa $(n=48)$. Consideram-na esporádica, concentrada nos períodos de defeso, e que os fiscais têm pouco conhecimento sobre a pesca na região e são truculentos com os pescadores.

\section{DISCUSSÃO}

A pesca na Baía da Babitonga se mostrou heterogênea. No que diz respeito aos aspectos técnicos, a posição das comunidades na região condiciona as práticas utilizadas e a importância dos recursos pesqueiros. Da mesma forma, pode afetar as opções de comercialização do pescado, principalmente pela presença do turismo e pela proximidade com áreas urbanas. Urbanização e turismo podem ainda influenciar o envolvimento dos pescadores com outras atividades econômicas fora da pesca, ao criar novas opções de trabalho.

A plataforma adjacente à Baía da Babitonga é a principal área de pesca dos pescadores da região, mas aqueles que possuem embarcações de maior porte e potência, como os de Baln. Barra do Sul, com 
embarcações que alcançam até $14 \mathrm{~m}$ de comprimento e motor com até $145 \mathrm{Hp}$ (Bastos, 2006), eventualmente podem se deslocar para outras regiões, como o litoral norte do Paraná e o litoral sul de São Paulo. As áreas de pesca são compartilhadas por pescadores da Baía da Babitonga, bem como de outras comunidades da pesca de pequena escala do litoral catarinense (Medeiros et al., 1997; Bail \& Branco, 2007) e do Paraná (Andriguetto-Filho, 2002; Chaves \& Robert, 2003), além da frota industrial (Pezzuto, 2001). Dentre as implicações pode-se destacar a existência de conflitos na região envolvendo diferentes pescarias (p.ex. arrasto e redes de emalhe), sejam entre os pescadores de pequena escala locais e de fora, ou com a frota industrial (Chaves \& Robert, 2009; Serafini, 2012).

No estuário, as comunidades situadas a partir do Porto de São Francisco do Sul em direção ao interior da baía não utilizam as áreas de pesca da plataforma. O gerival se destaca na captura do camarão-branco, principal recurso dos pescadores destas comunidades. As áreas de pesca se distribuem por todo o estuário, apesar da existência de pontos de pesca específicos (Meros do Brasil, 2011), e a porção central da baía é compartilhada por pescadores de diversas comunidades. Eventualmente podem também ocorrer conflitos entre os pescadores locais pela captura dos recursos, seja entre práticas diferentes (p.ex. gerival e caceio), com relação ao cumprimento da legislação (p.ex. do gerival), ou ainda com outras atividades, como os portos e a pesca recreativa (Serafini, 2012).

Em toda a Baía da Babitonga, predomina a unidade de produção familiar e a esposa ou companheira do pescador tem papel importante. Os filhos também participam, apesar de que os pais preferem que os mesmos se dediquem a outras atividades e os filhos gostariam de ter essa possibilidade. Bastos (2006) observou que isto é verdade para mais de $50 \%$ dos pais e mais de $70 \%$ dos filhos de pescadores da Baía da Babitonga, realidade esta também presente em outras comunidades de pescadores de Santa Catarina (Medeiros et al., 1997; Bail \& Branco, 2007).

A percepção geral de redução dos recursos pesqueiros na região, e o ambiente urbano do entorno da baía, que favorece a disponibilidade de outras atividades econômicas, estimulam o interesse dos pescadores e seus filhos para que estes procurem outras oportunidades. De fato, os próprios pescadores acabam por também realizar outras atividades econômicas fora da pesca, como forma complementar a renda, que pode variar conforme a comunidade/ município. Por exemplo, Bastos (2006) observou que nos municípios de Baln. Barra do Sul e Itapoá, nos quais os pescadores atuam principalmente na plataforma e sobre o camarão-sete-barbas, $15 \%$ e $23 \%$ dos pescadores, respectivamente, desenvolvem outras atividades. Já em Garuva e Araquari, onde os pescadores atuam somente no estuário e sobre recursos diversos, sazonais e por vezes de menor valor econômico, o percentual foi maior, $65 \%$ e $42 \%$, respectivamente.

O turismo é uma atividade econômica importante na Baía da Babitonga, seja aquele de "sol e praia" nos balneários da orla ou o da pesca recreativa, na plataforma (Schork et al., 2010) e principalmente dentro do estuário. No caso da pesca recreativa, os pescadores cada vez mais começam a investir na captura e manutenção de camarão para ser comercializado como isca-viva aos turistas, pois conseguem um melhor rendimento do que na comercialização para o consumo como alimento. A presença de turistas amplia as oportunidades de comercialização dos pescadores nos balneários da orla, e também daqueles situados nas comunidades próximas dos centros urbanos, que conseguem escoar a produção para peixarias e restaurantes ou para atravessadores que atendem ao mercado local (p.ex. as sedes dos municípios da região, principalmente Joinville) e regional (p.ex. Curitiba-PR). De fato, a diversificação de atividades é característica não somente dos pescadores de pequena escala desta região, mas de diversas outras no Brasil (Diegues, 2004) e de outros países em desenvolvimento (Berkes et al., 2001).

As evidências do presente trabalho, bem como da literatura sobre a pesca na região (IBAMA, 1998; Pinheiro \& Cremer, 2003; Bastos, 2006), indicam que a heterogeneidade da pesca na Baía da Babitonga se caracteriza por diferentes grupos de pescadores, que se distinguem pelas técnicas de pesca utilizadas, as áreas de atuação e as características socioeconômicas. No contexto deste trabalho, isto tem implicações pertinentes quanto à importância que os diferentes recursos explotados representam para os pescadores e nas relações estabelecidas entre estes e os outros atores locais e externos, o que afetará a sua percepção sobre o estabelecimento e cumprimento das instituições de gestão pesqueira. Ou seja, evidencia-se a necessidade de reconhecer a diversidade do contexto pesqueiro local para melhor ajustar as instituições de gestão às distintas realidades locais (Carlsson \& Berkes, 2005).

A atual organização dos pescadores e sua percepção sobre as instituições também tem implicações importantes para a gestão. A autopercepção dos pescadores de ser pouco unidos não implica necessariamente a ausência de solidariedade na pesca; mesmo assim, são vulneráveis a fatores econômicos que inibem as pescarias coletivas, como no caso da diminuição da pesca coletiva do arrastão de praia em favorecimento de pescarias mais individuais (assim como no Paraná - Pinheiro et al., 2010), mas sim 
uma baixa ação política coletiva, o que dificulta sua organização local. A satisfação parcial dos pescadores com as ações das Colônias, a baixa presença dos mesmos nas suas reuniões, o enfraquecimento das associações locais e a aparente ausência de lideranças, resultam nas dificuldades ou simples ausência de organização e mobilização política dos pescadores em defesa de seus direitos e da melhoria das condições da pesca.

Da mesma forma, a percepção que os pescadores têm de afastamento das agências do governo dos problemas locais, que se expressa, em parte, na própria dificuldade em reconhecê-las, reflete o reduzido esforço por parte do governo na mobilização local no sentido de compartilhar com os pescadores a responsabilidade pela resolução dos problemas da pesca. O maior reconhecimento da EPAGRI demonstra sua presença local, mas está fortemente relacionado aos benefícios diretos que os pescadores têm pelo acesso ao Pronaf. Já outros envolvimentos da EPAGRI com os pescadores, como, por exemplo, na execução do monitoramento participativo da pesca financiado pelo MPA (em 2009), expõem os seus limites institucionais de ação. Conflitos entre representantes do órgão e dos pescadores e a morosidade na implementação de algumas atividades desestimularam a participação dos pescadores (Foppa et al., 2011), comprometendo a qualidade das informações (Serafini, 2012).

As instituições que estabelecem os períodos de defeso, especialmente do camarão-sete-barbas, são contestadas pelos pescadores da Baía da Babitonga, assim como por outras comunidades do litoral centro-norte catarinense (Branco, 2005; Pezzuto et al., 2008) e de outras regiões do Sul-Sudeste (Franco et al., 2009; Andriguetto Filho et al., no prelo). Esta contestação resulta de uma percepção por parte dos pescadores da necessidade de alteração do período estipulado, com base em seu conhecimento local, o qual é corroborado pela literatura científica (Branco, 2005). O não atendimento desta demanda, que também está associado aos problemas de representatividade política nos espaços de tomada de decisão (Medeiros, 2009), gera conflitos entre os pescadores e as agências envolvidas na gestão, principalmente com os responsáveis pela fiscalização.

Estas situações acabam por enfraquecer o estabelecimento de relações de confiança entre os pescadores e o governo, favorecendo a percepção dos pescadores sobre a baixa abertura do governo para sua participação na tomada de decisões, apesar de entenderem que podem contribuir com o seu conhecimento das dinâmicas locais no processo de gestão. Por outro lado, sua baixa organização e ação política também contribuem para a manutenção desta situação. A percepção dos pescadores sobre o envol- vimento reduzido de outros agentes (p.ex. ONGs, pesquisadores), os quais teriam potencial para auxiliar na construção da sua capacidade de ação política (Seixas \& Berkes, 2010), dificulta ainda mais uma mudança no status quo dos arranjos institucionais e das relações sociais estabelecidas entre os atores (usuários e governo) envolvidos na gestão pesqueira local.

As evidencias apontam para uma fragilidade do atual modelo de gestão centralizado no governo. Ressalta-se a necessidade de uma mudança na perspectiva de gestão pesqueira na região: de uma centralização da tomada de decisões por parte do governo para a construção de instituições de gestão colaborativas, abrangendo governo, usuários e outros atores relevantes do contexto local. Arranjos institucionais colaborativos de gestão (p.ex. cogestão adaptativa -Armitage et al., 2007) podem ser modelos alternativos para melhor lidar com a complexidade do contexto pesqueiro local (Medeiros et al., 2013; Silva et al., 2013), aqui evidenciada pela heterogeneidade da pesca e pela fraqueza das atuais instituições de gestão.

\section{AGRADECIMENTOS}

À Coordenação de Aperfeiçoamento de Pessoal de Nível Superior (CAPES/REUNI) e ao Conselho Nacional de Desenvolvimento Científico e Tecnológico (CNPq) pela concessão de bolsa de doutorado a TZS (processo CNPq n 141361/2010-7). Aos pescadores, pesquisadores e técnicos da EPAGRI que atuam na região da Baía da Babitonga pelo auxílio com informações da região e colaboração no trabalho de campo. Ao Instituto HSBC de Solidariedade, pelo apoio financeiro.

\section{REFERÊNCIAS}

Andriguetto-Filho, J.M. 2002. Sistemas técnicos de pesca no litoral do Paraná: caracterização e tipificação. In: Raynaut, C.; Zanoni, M.; Lana, P.C.; Floriani, D.; Ferreira, A.D.D.; Andriguetto, J.M. (eds.) Desenvolvimento e Meio Ambiente - em busca da interdisciplinaridade. Editora da UFPR, Curitiba. 213-233pp.

Andriguetto-Filho, J.M.; Krul, R. \& Feitosa, S. 2014. Contradições históricas entre gestão e fomento e a evolução da pesca de arrasto de camarão na plataforma interna do Paraná. In: Haimovici, M.; Andriguetto-Filho, J.M.; Sunye, P. (orgs.) A pesca marinha e estuarina no Brasil: estudos de caso multidisciplinares. Editora da FURG, Rio Grande. 87-99 pp. 
Armitage, D.; Berkes, F. \& Doubleday, N. (eds.). 2007. Adaptive co-management: collaboration, learning, and multi-level governance. UBC Press, Canada, $344 p$.

Bail, G.C. \& Branco, J.O. 2007. Pesca artesanal do camarão sete-barbas: uma caracterização sócioeconômica na Penha, SC. Braz. J. Aquat. Sci. Technol. 11(2): 25-32.

Bastos, G.C. 2006. Atividade pesqueira na Baía da Babitonga. In: Cremer, M.J.; Morales, P.R.D.; Oliveira, T.M.N. de (orgs.) Diagnóstico ambiental da Baía da Babitonga. Editora UNIVILLE, Joinville. 200-244pp.

Berkes, F. 2003. Alternatives to conventional management: lessons from small-scale fisheries. Environment. 31(1): 5-19.

Berkes, F.; Mahon, R.; McConney, P.; Pollnac, R. \& Pomeroy, R. 2001. Managing small-scale fisheries: alternative directions and methods. International Development Research Centre, Ottawa, Canada, 309p.

Branco, J.O. 2005. Biologia e pesca do camarão setebarbas Xiphopenaeus kroyeri (Heller) (Crustacea, Penaeidae), na Armação do Itapocoroy, Penha, Santa Catarina, Brasil. Rev. Bras. Zool. 22(4): 1050-1062.

Carlsson, L. \& Berkes, F. 2005. Co-management: concepts and methodological implications. J. Environ. Manage. 75: 65-76.

Castello, L. 2008. Re-pensando o estudo e o manejo da pesca no Brasil. Pan. Am. J. Aquat. Sci. 3(1): $17-22$.

Chaves, P. de T. \& Robert, M. de C. 2003. Embarcações, artes e procedimentos da pesca artesanal no litoral sul do Estado do Paraná, Brasil. Atlântica. 25(1): 53-59.

Chaves, P. de T. \& Robert, M. de C. 2009. Extravio de petrechos e condições para a ocorrência de pesca-fantasma no litoral norte de Santa Catarina e sul do Paraná. Bol. Inst. Pesca. 35(3): 513-519.

Chuenpagdee, R. \& Jentoft, S. 2007. Step zero for fisheries co-management: what precedes implementation. Mar. Policy. 31: 657-668.

Cremer, M.J.; Morales, P.R.D. \& Oliveira, T.M.N. de (orgs.). 2006. Diagnóstico ambiental da Baía da Babitonga. Editora UNIVILLE, Joinville. 256p.

Diegues, A.C. 2004. A pesca construindo sociedades. Núcleo de Apoio à Pesquisa Sobre Populações Humanas e Áreas Úmidas Brasileiras/USP, São Paulo, 315p.

Foppa, C.C.; Bonatti, S.; Medeiros, R.P. \& Borgonha, M. 2011. Monitoramento participativo da pesca artesanal marinha do estado de Santa Catarina: desafios sociopolíticos. In: V Simpósio Brasileiro de Oceanografia, Santos-SP.
Franco, A.C.N.P.; Schwarz Junior, R.; Pierri, N. \& Santos, G.C. dos. 2009. Levantamento, sistematização e análise da legislação aplicada ao defeso da pesca de camarões para as regiões sudeste e sul do Brasil. Bol. Inst. Pesca. 35(4): 687-699.

IBAMA. 1998. Proteção e controle de ecossistemas costeiros: manguezal da Baía de Babitonga. IBAMA. Coleção meio ambiente. Série estudos pesca, n. 25, Brasília, 146p.

Isaac, V.J.; Martins, A.S.; Haimovici, M. \& Andriguetto, J.M.A (orgs.). 2006. A pesca marinha e estuarina do Brasil no início do Século XXI: recursos, tecnologias, aspectos socioeconômicos e institucionais. Editora Universitária UFPA, Belém, $188 p$.

Johannes, R.E. 1998. The case for data-less marine resource management: examples from tropical nearshore finfisheries. Trends Ecol. Evol. 13(6): 243-246.

Knie, L.W. (coord.). 2003. Atlas ambiental da região de Joinville: complexo hídrico da Baía da Babitonga. $2^{\circ}$ Ed., FATMA/GTZ, Florianópolis.

Mahon, R.; McConney, P. \& Roy, R.N. 2008. Governing fisheries as complex adaptive systems. Mar. Policy. 32: 104-112.

Medeiros, R.P. 2009. Possibilidades e obstáculos à co-gestão adaptativa de sistemas pesqueiros artesanais: estudo de caso na área da Baía de Tijucas, litoral centro-norte do estado de Santa Catarina, no período de 2004 a 2008. Tese de Doutorado. Universidade Federal de Santa Catarina - UFSC. 337p.

Medeiros, R.P.; Guanais, J.H.D.G.; Santos, L.deO.; Spach, H.L.; Silva, C.N.S.; Foppa, C.C.; Cattani, A.P. \& Rainho, A.P. 2013. Estratégias para a redução da fauna acompanhante na frota artesanal de arrasto do camarão sete-barbas: perspectivas para a gestão pesqueira. B. Inst. Pesca. 39(3): 339-358.

Medeiros, R.P.; Polette, M.; Vizinho, S.C.; Macedo, C.X. \& Borges, J.C. 1997. Diagnóstico sócioeconômico e cultural nas comunidades pesqueiras artesanais do litoral centro-norte do estado de Santa Catarina. Notas Téc. FACIMAR. 1: 33-42.

Meros do Brasil. 2011. Mapeamento participativo dos recursos pesqueiros na área de influência do Terminal Marítimo Mar Azul - porção sul do eixo central da Baía da Babitonga. 14p. Disponível em: http://www.merosdobrasil.org/. Acessado em: out./2012.

MPA. 2012. Boletim do Registro Geral da Atividade Pesqueira-RGP. Ministério da Pesca eAquicultura, Brasília, 50p. 
Pezzuto, P.R. 2001. Projeto de "Análise e diagnóstico da pesca artesanal e costeira de camarões na região sul do Brasil: subsídios para um ordenamento". Braz. J. Aq. Sci. Tecnol., 5: 41-44.

Pezzuto, P.R.; Alvarez-Perez, J.A. \& Wahrlich, R. 2008. The use of the swept area method for assessing the seabob shrimp Xiphopenaeus kroyeri (Heller, 1862) biomass and removal rates based on artisanal fishery derived data in southern Brazil: using depletion models to reduce uncertainty. Lat. Am. J. Aquat. Res. 36(2): 245-257.

Pinheiro, L. \& Cremer, M. 2003. Sistema pesqueiro da Baía da Babitonga, litoral norte de Santa Catarina: uma abordagem etnoecológica. Desenv. Meio Amb. 8: 59-68.

Pinheiro, L.; Lana, P. da C.; Andriguetto-Filho, J.M. \& Hanazaki, N. 2010. Pesca de pequena escala e a gestão patrimonial: o caso da pesca da tainha no litoral paranaense. Desenvolv. Meio Ambiente 21: 143-155.

PROZEE - Fundação de Amparo a Pesquisa de Recursos Vivos na Zona Economicamente Exclusiva. 2006. Monitoramento da atividade pesqueira no litoral do Brasil - Relatório técnico final. Convênio SEAP/PROZEE/IBAMA $n^{\circ}$ 109/2004, Brasília, 328p.

Schork, G.; Mottola, L.S.M. \& Hostim Silva, M. 2010. Diagnóstico da pesca amadora embarcada na região de São Francisco do Sul (SC). Rev. CEPSUL - Biod. Conserv. Mar. 1(1): 8-17.

Seixas, C.S. \& Berkes, F. 2010. Community-based enterprises: the significance of partnerships and institutional linkages. Int. J. Commons. 4(1): 183-121.
Serafini, T.Z. 2012. Limites e possibilidades para a construção da gestão compartilhada da pesca marinha-estuarina: estudo de caso do sistema socioecológico pesqueiro da Baía da BabitongaSC. Tese de Doutorado. Universidade Federal do Paraná - UFPR. 232p.

Silva, C.N.S.; Broadhurst, M.K.; Medeiros, R.P. \& Dias, J. H. 2013. Resolving environmental issues in the southern Brazilian artisanal penaeid- trawl fishery through adaptive co-management. Mar. Policy. 42: 133-141.

Sunye, P.S. 2006. Diagnóstico da pesca no litoral do estado de Santa Catarina. In: Isaac, V.J.; Martins, A.S.; Haimovici, M.; Andriguetto, J.M. (orgs.) A pesca marinha e estuarina do Brasil no início do Século XXI: recursos, tecnologias, aspectos socioeconômicos e institucionais. Editora Universitária UFPA, Belém. 141-15 pp.

Vasconcellos, M.; Diegues, A.C. \& Sales, R.R. de. 2007. Limites e possibilidades na gestão da pesca artesanal costeira. In: Costa, A.L. (org.) Nas redes da pesca artesanal. IBAMA, Brasília. 2-70pp.

Submetido: Novembro/2012 Revisado: Outubro/2013 Aceito: Novembro/2013 